\title{
Informação de perícias médicas para subsidiar ações de vigilância e promoção da saúde dos servidores públicos: o caso de uma universidade pública federal do Brasil
}

\section{Information from official medical examinations to support actions aiming the civil servant health surveillance and promotion: the case of a federal public university in Brazil}

\section{Información de peritajes médicos para auxiliar acciones de vigilancia y promoción de la salud de los funcionarios: el caso de una universidad pública federal en Brasil}

Tirze Barbalho Krolls ${ }^{1, a}$

tirzekrolls@yahoo.com.br | https://orcid.org/0000-0003-0031-0589

Nadi Helena Presser, $, 2, b$

nadihelena@uol.com.br | https://orcid.org/oooo-00o2-1585-117X

Nancy Sánchez-Tarragóón ${ }^{3, c}$

nancy.sanchez@ufrn.br | https://orcid.org/0000-0002-5114-6072

${ }^{1}$ Universidade Federal Rural de Pernambuco, Pró-Reitoria de Gestão de Pessoas. Departamento de Qualidade de Vida. Recife, PE, Brasil.

2 Universidade Federal de Pernambuco, Centro de Artes e Comunicação, Departamento da Ciência da Informação. Recife, PE, Brasil.

${ }^{3}$ Universidade Federal de Rio Grande do Norte, Centro de Ciências Sociais Aplicadas, Departamento de Ciência da Informação. Natal, RN, Brasil

Mestrado em Gestão Pública para o Desenvolvimento do Nordeste pela Universidade Federal de Pernambuco.

${ }^{\mathrm{b}}$ Doutorado em Engenharia de Produção pela Universidade Federal de Santa Catarina.

c Doutorado em Información Científica y Documentación pela Universidad de Granada.

\section{RESUMO}

O estudo apresentado neste artigo teve como objetivo geral propor ações de vigilância e promoção da saúde dos servidores da Universidade Federal Rural de Pernambuco (UFRPE), com base nas informações de perícias médicas registradas, no período de 2016 a 2018, no prontuário eletrônico do Subsistema Integrado de Atenção à Saúde do Servidor (SIASS). Para isso, o estudo descreve o perfil de morbidade dos servidores que buscaram a perícia médica, analisa os principais fatores de risco no ambiente de trabalho e sua relação com o perfil de morbidade revelado, de modo a estabelecer prioridades para ações de educação e promoção da saúde. As ações propostas abrangem estudos ergonômicos, avaliação e acompanhamento psicológicos, capacitação, entre outras, para intervir nas principais doenças identificadas (psíquicas e osteomusculares). As informações registradas no módulo de Perícias Médicas do SIASS, até então subutilizadas, revelaram suas potencialidades, pois permitiram identificar os problemas e propor a tomada de decisões gerenciais em prol da prevenção de doenças e da melhoria da saúde dos servidores.

Palavras-chave: Perícia médica; Serviços de saúde do trabalhador; Sistemas de informação em saúde; Promoção da saúde; Vigilância em saúde do trabalhador.

\section{ABSTRACT}

The purpose of the study presented in this article was to propose actions aiming the civil servant health surveillance and promotion in the UFRPE - Universidade Federal Rural de Pernambuco (Federal Rural 
University of Pernambuco), Brazil, based on information about the official medical examination included from 2016 to 2018 in electronic health records of the SIASS - Subsistema Integrado de Atenção à Saúde do Servidor (Integrated Subsystem of civil servant Healthcare). The study describes the morbidity profile of diseases in civil servants who requested the official medical examination, analyzes the main risk factors in the workplace and their relationship with that morbidity profile to establish priorities to the actions aiming health education and promotion. The proposed actions include ergonomic studies, psychological evaluation and monitoring, training, among others, to intervene in the main identified diseases (psychic and musculoskeletal). The information registered in the SIASS official medical examination module, which before was underused, revealed its potential, since it allowed to identify the problems and to propose decision-making regarding the prevention of diseases and the improvement in health for the benefit of the civil servants.

Keywords: Official medical examination; Occupational health services; Health information systems. Health promotion; Surveillance of the workers health.

\title{
RESUMEN
}

El estudio presentado en este artículo ha tenido como su objetivo general proponer acciones de vigilancia y promoción de la salud de los funcionarios de la UFRPE - Universidade Federal Rural de Pernambuco (Universidad Federal Rural de Pernambuco), Brasil, basado en las informaciones de peritajes médicos registradas, desde 2016 hasta 2018, en historias clínicas electrónicas del SIASS - Subsistema Integrado de Atenção à Saúde do Servidor (Subsistema Integrado de Atención de Salud del Funcionario). El estudio describe el perfil de morbilidad de los funcionarios que solicitaron peritajes médicos, analiza los principales factores de riesgo en el lugar de trabajo y su relación con el perfil de morbilidad descubierto, con el fin de establecer prioridades para la educación y promoción de la salud. Las acciones propuestas incluyen estudios ergonómicos, evaluación y acompañamiento psicológicos, capacitación, entre otras, para intervenir en las principales enfermedades identificadas (psíquicas y osteomusculares). Las informaciones registradas en el módulo de pericias médicas del SIASS, hasta entonces poco utilizadas, revelaron su potencial, puesto que permitieron identificar los problemas y proponer la toma de decisiones gerenciales en beneficio de la prevención de enfermedades y de la mejora de la salud de los funcionarios.

Palabras clave: Peritaje médico; Servicios de salud del trabajador; Sistemas de información acerca de la salud; Promoción de salud; Vigilancia de la salud del trabajador.

INFORMAÇÕES DO ARTIGO

\begin{abstract}
Contribuição dos autores:
Concepção e desenho do estudo: Tirze Barbalho Krolls; Nadi Helena Presser; Nancy Sánchez-Tarragó.

Aquisição, análise ou interpretação dos dados: Tirze Barbalho Krolls; Nadi Helena Presser; Nancy Sánchez-Tarragó.

Redação do manuscrito: Tirze Barbalho Krolls; Nadi Helena Presser; Nancy Sánchez-Tarragó.

Revisão crítica do conteúdo intelectual: Tirze Barbalho Krolls; Nancy Sánchez-Tarragó; Nadi Helena Presser.
\end{abstract}

Declaração de conflito de interesses: não há

Fontes de financiamento: não houve.

Considerações éticas: Esta pesquisa foi aprovada pelo Comitê de Ética em Pesquisa CEP/UFPE em dezembro/2019, parecer n³782266.

Agradecimentos/Contribuições adicionais: a Alejandro Caballero Rivero pela colaboração nas análises estatísticas e na elaboração de visualizações e figuras.

Histórico do artigo: submetido: 5 out. 2020 | aceito: 16 abr. 2021 | publicado: 31 ago. 2021.

Apresentação anterior: não há

Licença CC BY-NC atribuição não comercial. Com essa licença é permitido acessar, baixar (download), copiar, imprimir, compartilhar, reutilizar e distribuir os artigos, desde que para uso não comercial e com a citação da fonte, conferindo os devidos créditos de autoria e menção à Reciis. Nesses casos, nenhuma permissão é necessária por parte dos autores ou dos editores. 
Reciis - Revista Eletrônica de Comunicação, Informação \& Inovação em Saúde, Rio de Janeiro, v. 15, n. 3, p. 680-702, jul.-set. 2021 [www.reciis.icict.fiocruz.br] e-ISSN 1981-6278

\section{INTRODUÇÃO}

A saúde do trabalhador constitui uma área da saúde pública que tem como objeto de estudo e intervenção as relações entre o trabalho e a saúde. Na condição de prática social, as ações de saúde do trabalhador apresentam dimensões sociais, políticas e técnicas indissociáveis. No Brasil, é a partir da criação do Sistema Único de Saúde (SUS) que se fortalece um novo paradigma de saúde do trabalhador alicerçado nos conceitos de promoção, vigilância e participação em saúde. Nas décadas de 1990 e de 2000 se produzem intensas discussões relacionadas com políticas e regulamentação neste âmbito que culminam com a Política Nacional de Saúde do Trabalhador e da Trabalhadora (PNSTT), em 2012. Já, com relação aos servidores públicos, até a década de 2000 não existia um sistema com informações de saúde que possibilitasse traçar o perfil de adoecimento dos servidores e suas condições de trabalho com vistas a alinhar a área da saúde e a política de gestão dos recursos humanos (BRASIL, 2008). Em 2006, funda-se o Sistema de Saúde Ocupacional do Servidor Público (SISOSP), que, logo em 2009, é substituído pelo Subsistema Integrado de Atenção à Saúde do Servidor (SIASS) no marco de uma Política de Atenção à Saúde e Segurança do Servidor (PASS). O SIASS se fundamenta nos eixos de assistência à saúde; perícia oficial em saúde; promoção, prevenção e vigilância em saúde dos servidores.

Em muitas universidades, como é o caso da Universidade Federal Rural de Pernambuco (UFRPE), as informações relativas à saúde dos servidores são coletadas a partir da realização das perícias oficiais em saúde (também chamadas de perícias médicas), executadas no SIASS e registradas no prontuário eletrônico do módulo de Perícia em Saúde, disponível no banco de dados Sistema Integrado de Administração Pessoal SIAPENET - SIAPE SAÚDE. O sistema viabiliza a consolidação de informações periciais de licenças médicas e odontológicas, de acidentes de trabalho, de doenças profissionais, de aposentadorias por invalidez e de readaptações funcionais. Perícia oficial em saúde "é o ato administrativo que consiste na avaliação técnica de questões relacionadas à saúde e à capacidade laboral, realizada na presença do periciado por médico ou cirurgião-dentista formalmente designado" (BRASIL, 2017, p. 8). O objetivo é subsidiar a Administração Pública Federal na fundamentação de decisão a que está obrigada.

A partir da análise do registro dos dados de licenças e afastamentos vindos das perícias médicas, é possível também nortear ações específicas de assistência médica, assim como subsidiar a elaboração de políticas públicas de vigilância e prevenção de doenças relacionadas ou não ao trabalho dos servidores e de promoção da saúde.

Na UFRPE, a partir de janeiro de 2016, todas as perícias realizadas passaram a ser registradas no SIASS, mais propriamente nos seus prontuários eletrônicos, pelos profissionais autorizados: os peritos oficiais em saúde. Assim foi-se construindo uma série histórica de informações sobre o adoecimento dos servidores, com potencialidade para servir de base para diversos estudos epidemiológicos sobre a saúde dos professores e dos servidores técnicos administrativos. Contudo, até outubro de 2020, essas informações não vinham sendo utilizadas por profissionais do Departamento de Qualidade de Vida (DQV) da UFRPE, embora tenham competência e atribuições para análise, interpretação e consequente formulação de propostas para orientar políticas, bem como ações institucionais, no contexto dessa universidade. Nessas condições, as atividades das Unidades SIASS resumiam-se à coleta e ao armazenamento de informações - estoques de informação -, sem que cumprissem a sua função basilar, que é a de informar para construir conhecimento e levar à ação.

Vê-se, portanto, a possibilidade de focar a saúde do servidor e, por meio da análise das informações disponíveis, identificar e procurar evitar as doenças mais frequentes, ainda que as ações de promoção da saúde realizadas no DQV da UFRPE sempre tivessem dado preferência à comunidade estudantil. Portanto, o objetivo geral do estudo ora apresentado foi propor ações de vigilância e promoção da saúde voltadas para 
os servidores dessa universidade, de modo a prevenir os principais riscos no ambiente de trabalho a partir da análise do perfil de morbidade dos servidores tal como registrado nos prontuários eletrônicos de perícias médicas. Para dar conta do objetivo geral, este estudo descreveu o perfil de morbidade dos servidores que buscaram a perícia médica, segundo o cargo; analisou os principais fatores de risco no ambiente de trabalho e sua relação com o perfil de morbidade; e estabeleceu prioridades para ações de educação e promoção da saúde. Toda a pesquisa foi realizada mediante o uso das informações de perícia oficial em saúde disponíveis no SIASS. Isso evidencia como a gestão das informações em saúde respalda a tomada de decisões de elevada responsabilidade e relevância social.

\section{O SUBSISTEMA INTEGRADO DE ATENÇÃO À SAÚDE DO SERVIDOR - SIASS}

A preocupação com a saúde do trabalhador e a emergência de ciências a ela relacionadas começou na segunda metade do século XIX, na Inglaterra, com a Revolução Industrial. A área evoluiu da Medicina do Trabalho, concentrada em resolver as "avarias" do corpo dos operários para devolvê-los ao processo produtivo (ZANIN; PERNA; KÜNZLE; MUNSTCH, 2015), para a Saúde Ocupacional, com foco na intervenção no local de trabalho, até chegar à Saúde do Trabalhador, na qual se considera que os agravos à saúde das pessoas que trabalham não advêm exclusivamente do local de trabalho, mas de todas as circunstâncias possíveis do meio ambiente. Por outro lado, o processo saúde/doença passou logo a ser assumido não como a simples soma das condições orgânicas e sociais de cada indivíduo isoladamente, mas como a expressão de um processo social mais amplo, que resulta de uma complexa trama de fatores e relações. Isso quer dizer que os mesmos fatores que possibilitam ao homem viver (alimento, água, ar, clima, habitação, trabalho, tecnologia, relações familiares e sociais) podem causar doença, se agem com determinada intensidade, se pesam em excesso ou faltam, ou se agem sem controle (BERLINGUER, 1988; NARVAI; SÃO PEDRO, 2013).

Portanto, entende-se por doença profissional aquela contraída, exclusivamente, pelo exercício do trabalho, em especial, aquelas adquiridas em consequência das precárias condições do ambiente de trabalho agravado pelas tarefas executadas. Todavia, a caracterização da doença profissional não é de fácil constatação, requerendo análise específica de cada caso, buscando concluir se guardam uma relação direta com as atividades exercidas ou estão ligadas a outros fatores que não apresentam relação com as atividades laborativas exercidas pelo profissional.

No Brasil, foi com a Constituição de 1988 que as políticas de proteção social e de regulação do trabalho se universalizaram, superando também a dicotomia entre direitos trabalhistas e previdenciários e condições de vida e saúde no trabalho. A criação do Sistema Único de Saúde (SUS) e do Regime Jurídico Único (RJU) de acordo com a Lei.8112/90, que deu origem ao arcabouço jurídico-institucional para o serviço público, são exemplos dessas conquistas sociais (MARTINS et al., 2017).

A criação do SUS, tal como descrito na Lei $\mathrm{n}^{0}$ 8.080, de 19 de setembro de 1990, fortaleceu um novo paradigma de Saúde do Trabalhador alicerçado nos conceitos de promoção, vigilância e participação em saúde. Saúde do Trabalhador, então, foi definida como "o conjunto de atividades que se destina, através das ações de vigilâncias epidemiológica e sanitária, à promoção e proteção da saúde dos trabalhadores, assim como visa à recuperação e reabilitação da saúde dos trabalhadores submetidos aos riscos e agravos advindos das condições de trabalho" (BRASIL, 1990). Entre 1990 e 2000 houve um intenso debate sobre a regulamentação da saúde do trabalhador no âmbito do SUS que culminou, em 2011, com a Política Nacional de Saúde e Segurança do Trabalho (PNSST), Decreto Lei $\mathrm{n}^{0}$ 7.602, de 7 de dezembro de 2011, e, em 2012, com a Política Nacional de Saúde do Trabalhador (MARTINS et al., 2017).

Com relação aos servidores públicos, a partir dos anos 2000, num cenário de mudanças tecnológicas e econômicas, com aumento de acidentes e doenças do trabalho, reivindicações dos movimentos da sociedade 
civil organizada, como os dos sindicatos e outros, o Estado se vê pressionado "a estruturar e implementar outras políticas de saúde e segurança para esta categoria” (RAMMINGER; NARDI, 2007, p. 218). Até então, não existia um sistema com informações de saúde que viabilizasse traçar o perfil de adoecimento dos servidores e das reais condições de trabalho no setor público federal e, além disso, aproximar as áreas da saúde e da política de gestão dos recursos humanos (BRASIL, 2008). Para isso, em 2006, o Ministério do Planejamento instituiu o Sistema de Saúde Ocupacional do Servidor Público (SISOSP), ainda alicerçado numa proposta restrita de saúde ocupacional, "com foco na preservação da força de trabalho e restrita às atividades de assistência, fiscalização, perícias médicas, exames periódicos e prevenção de acidentes e doenças decorrentes do trabalho" (MARTINS et al., 2017, p. 1430).

Em 2008, no marco da discussão sobre uma Política de Atenção à Saúde do Servidor Público Federal (PASS), se propõe sua implantação sob a forma de um Sistema de Atenção à Saúde do Servidor (SIASS), com eixos na assistência à saúde do servidor, perícia em saúde, promoção e vigilância da saúde.

OSIASS trouxe uma reformulação que possibilitou avançar da concepção tradicional da saúde ocupacional para o conceito de saúde do trabalhador. Seu objetivo é executar ações de promoção e acompanhamento da saúde dos servidores, prevenção dos agravos, perícia e assistência (MARTINS et al., 2017). Segundo essa concepção, a saúde do trabalhador abrange "diversas situações em que o trabalhador pode ficar exposto a agentes químicos, físicos, mecânicos ou biológicos e, em decorrência, pode apresentar agravos à sua saúde como acidentes típicos do trabalho ou doenças ocupacionais" (NARDOCCI et al., 2013, p. 109). Estudos apontam que doenças que afetam os trabalhadores podem ainda ser originadas por fatores menos visíveis ou evidentes, como os psicossociais, a organização do trabalho, os turnos do trabalho (diurno e noturno, finais de semana), questões ergonômicas (MENDES; DIAS, 1991; FISCHER; MORENO; ROTENBERG, 2003; (NARDOCCI et al., 2013).

Para a implantação do SIASS, foi prevista a criação de unidades de referência em todos os estados do país que permitiriam a prestação de serviços de perícia oficial de saúde, vigilância em saúde e promoção da saúde. As universidades federais eram as mais bem estruturadas em relação aos serviços de saúde e à composição de uma equipe multiprofissional. Por isso, em muitos estados, elas ficaram à frente dos projetos de implantação do SIASS (TAISSUKE, 2016).

Os três eixos - assistência à saúde, vigilância da saúde dos servidores e perícia oficial em saúde - estão inter-relacionados (BRASIL, 2009). Inicialmente, as ações de promoção da saúde têm como finalidade a melhoria dos ambientes e dos processos de trabalho, de modo a ampliar a conscientização, a responsabilidade e a autonomia dos servidores (BRASIL, 2013). A vigilância da saúde do servidor se constitui de ações para detectar, conhecer, pesquisar, analisar e monitorar os fatores determinantes e condicionantes da saúde relacionados aos ambientes e aos processos de trabalho, tendo por objetivo reduzir os riscos ou agravos à saúde (BRASIL, 2014). Portanto, a identificação de fatores condicionantes ou fatores de risco (biológicos, químicos, físicos, ergonômicos) e o monitoramento de doenças e outros eventos de saúde propiciam subsidiar não apenas ações de controle, mas também de promoção e prevenção. Por sua vez, o papel desempenhado pela perícia oficial em saúde tem relevada importância social. Atua no sentido de assegurar os direitos do servidor quanto às suas necessidades de afastamento do trabalho por motivo de doença e outros especificados em lei, sem prejuízo em sua remuneração e em seus benefícios (BRASIL, 2017).

A perícia oficial em saúde, como mencionado anteriormente, "é o ato administrativo que consiste na avaliação técnica de questões relacionadas à saúde e à capacidade laboral, realizada na presença do periciado por médico ou cirurgião-dentista formalmente designado" (BRASIL, 2017, p. 8). O médico ou o cirurgiãodentista que efetua o ato pericial é o Perito Oficial em Saúde. Após os exames periciais necessários, a perícia oficial em saúde emite laudos ou pareceres que servirão de fundamentação nas decisões das licenças por motivos de saúde. Licença por motivo de saúde é o "o direito de o servidor ausentar-se, sem prejuízo da 
remuneração a que fizer jus, dentro dos prazos previstos, conforme a legislação vigente" (BRASIL, 2017, p. 10). O perito também atua para defender o interesse da administração pública federal, não permitindo favorecimentos ilegítimos na busca de ganhos secundários, e ainda fornece respaldo técnico e científico para decisões administrativas.

A partir da análise do registro dos dados de licenças e afastamentos vindos das perícias médicas, é possível nortear ações específicas de assistência médica, assim como subsidiar a elaboração de políticas públicas de vigilância e prevenção de doenças relacionadas ou não ao trabalho dos servidores, assim como políticas de promoção da saúde.

Uma revisão sistemática de literatura recente tem mostrado que a utilização dos prontuários eletrônicos na atenção e vigilância da saúde pode facilitar um incremento da produtividade/eficiência em processos e procedimentos; um aumento na qualidade dos dados (dados mais precisos, menos erros), assim como melhoria no gerenciamento de dados (os profissionais da saúde puderam acessar os dados do paciente de maneira mais eficiente). Contudo, em menor medida, algumas barreiras têm sido identificadas; por exemplo, dados ausentes ou não preenchidos; preenchimento incorreto de dados; falta de interoperabilidade e, portanto, de capacidade de compartilhamento entre diferentes sistemas, e perda de produtividade que ensinem os usuários a usar os prontuários eletrônicos (KRUSE; STEIN; THOMAS; KAUR, 2018).

\section{A UNIVERSIDADE FEDERAL RURAL DE PERNAMBUCO E AS INFORMAÇÕES DE PERÍCIA EM SAÚDE}

Na Universidade Federal Rural de Pernambuco (UFRPE) funciona uma unidade do SIASS instituída com uma equipe formada por um corpo técnico especializado dentro das áreas de atuação definidas pela PASS. Essa unidade está vinculada ao Departamento de Qualidade de Vida (DQV), integrado à PróReitoria de Gestão de Pessoas (PROGEPE). O DQV é constituído por uma Divisão de Saúde e Segurança do Trabalho (DSS), formada por dois engenheiros de segurança do trabalho, um médico do trabalho, um técnico de segurança do trabalho; uma Divisão de Assistência à Saúde do Servidor (DAS), formada por cinco médicos nas especialidades de cardiologia, clínica médica, ginecologia e psiquiatria, três psicólogas, uma assistente social, dois enfermeiros, dois técnicos de enfermagem, três dentistas e técnicos de saúde bucal; e, um laboratório de Exames Hematológicos e Bioquímicos, formado por três farmacêuticos e técnicos de laboratório.

Quanto ao trabalho de perícia médica, todos os médicos do DQV foram designados Peritos Oficiais da unidade SIASS. O processo de atendimento na perícia em saúde inicia quando o servidor (aqui denominado periciando) necessita de afastamento do trabalho por doença ou acidente. Para agendar sua perícia, o periciando comparece ao DVQ munido de seu atestado médico, ou se comunica com o DQV por meio de telefone ou e-mail e agenda sua perícia com o responsável técnico administrativo do setor. Ao final do atendimento, o servidor recebe laudo contendo o resultado da perícia, sinalizando deferimento ou não da sua licença médica. O laudo sinaliza também a necessidade ou não de reavaliação pericial e, se esta for considerada necessária, a data de comparecimento para sua realização. As licenças médicas ou odontológicas de até cinco dias num período de 12 meses não precisam ser periciadas e são registradas no sistema SIASS pelo servidor administrativo do DQV (BRASIL, 2017). Como mencionado anteriormente, a partir de janeiro de 2016, todas as perícias realizadas na UFRPE passaram a ser registradas no SIASS.

O registro das perícias em saúde se realiza no SIAPE SAÚDE, criado em 1989 para centralizar informações sobre folhas de pagamento vinculadas aos órgãos das administrações direta, fundacional e autárquica do Poder Executivo. Embora o sistema esteja sendo substituído pelo SIGEPE (Sistema de Gestão de Pessoas do Governo Federal), a plataforma online SIAPE net ainda está em funcionamento para alguns serviços. Um deles é o acesso ao SIAPE SAÚDE (informações de saúde e segurança do trabalho), que é viabilizado por 
meio do portal do SIASS: https://www2.siapenet.gov.br/saude/portal/public/index.xhtml (Acesso Seguro - Login). O acesso também poderá ocorrer digitando o endereço: https://www2.siapenet.gov.br/saude/. O SIAPE SAÚDE foi concebido e desenvolvido para automatizar as informações de saúde do servidor público federal. Os dados funcionais e pessoais dos servidores são recuperados de sua base e passam a compor o prontuário eletrônico de saúde do servidor (BRASIL, 2013).

O módulo Saúde e Segurança do Trabalho propicia o acesso às informações de perícias em saúde, exames periódicos e promoção da saúde do servidor público federal. Com relação às perícias em saúde, no módulo Perícias Médicas se viabiliza a consolidação de informações periciais de licenças médicas e odontológicas, de acidentes de trabalho, de doenças profissionais, de aposentadorias por invalidez e de readaptações funcionais. Possibilita também a marcação de perícias via internet, a indicação técnica do número de dias para afastamento, além de outras funcionalidades. Apenas os peritos oficiais em saúde designados para a unidade SIASS de determinada universidade têm acesso ao sistema.

Para realizar a perícia do servidor, o médico perito ou o responsável pela junta médica oficial deve primeiro acessar o sistema SIAPE SAÚDE, com seu respectivo CPF e senha. A seguir, entra no módulo Perícias Médicas, na agenda do dia. Nessa agenda já estão registrados os servidores que deverão realizar perícia nessa data, pois a agenda também é acessada pelo servidor técnico administrativo autorizado pela Diretoria do DQV da UFRPE.

Ao acessar o nome do servidor, o sistema abre um prontuário eletrônico no qual o perito ou a junta médica oficial registra todos os dados clínicos do periciando: anamnese com descrição de sintomas e história clínica, resultados de exames complementares e descrição do exame físico, diagnósticos, recomendações e conclusão pericial. Ao concluir a perícia, o perito ou a junta médica oficial deferem ou não o pleito do servidor. O laudo (que já é previamente formatado no sistema) é, então, emitido em duas vias e assinado pelos profissionais responsáveis; uma das vias é entregue ao servidor e a outra é arquivada em prontuário físico do servidor no DQV.

\section{PROCEDIMENTOS METODOLÓGICOS}

Como já mencionado, o objetivo do estudo aqui apresentado é propor ações de vigilância e promoção da saúde dos servidores da UFRPE, utilizando as informações da perícia oficial em saúde. Sendo assim, a pesquisa tem uma etapa descritiva (identificar e descrever agravos e doenças que mais acometem os servidores públicos dessa universidade e se estes agravos estão relacionados com o trabalho ou não) e uma etapa de intervenção (propor um plano de ações de vigilância e promoção da saúde).

Nesse sentido, o presente estudo analisou informações coletadas nos prontuários médicos de perícia médica dos servidores da UFRPE. Os dados foram acessados a partir de prontuários eletrônicos registrados durante o período de 2016 a 2018 no sistema SIAPE SAÚDE, no módulo Perícia Médica. A pesquisa abarcou as 1.232 perícias médicas realizadas e registradas no referido período. A fim de alcançar os objetivos propostos, os dados selecionados de cada servidor foram: idade, sexo, cargo, lotação, tipo de licença, tempo de serviço público no cargo, dias perdidos, classificação por tipo e grupo de doenças e tipo de exposição a risco ocupacional. A distribuição por tipo de doença ou grupo de doenças é feita de acordo com a Classificação Estatística Internacional de Doenças (CID) em sua décima revisão chamada CID1o (OMS,1997). A CID 10 fornece códigos relativos à classificação de doenças e de uma grande variedade de sinais, sintomas, aspectos anormais, queixas, circunstâncias sociais e causas externas para ferimentos ou doenças. A cada estado de saúde é atribuída uma categoria única à qual corresponde um código CID 10.

Foram coletadas ainda informações dos servidores que estavam expostos a riscos específicos no ambiente de trabalho, os quais são classificados em riscos biológicos, químicos, físicos e ergonômicos. Dentro dos riscos ergonômicos, foram levados em consideração os fatores psicossociais e cognitivos. Esses dados não 
estavam presentes nos prontuários de perícia médica do SIAPENET e foi preciso buscá-los na tabela de acompanhamento de concessão de adicionais de periculosidade, insalubridade e penosidade da Divisão de Saúde e Segurança do Trabalho (DSST) da UFRPE (acesso em dezembro de 2019).

Neste estudo, foram objeto de análise somente as licenças para tratamento da própria saúde do servidor e as licenças por acidente em serviço, ambas concedidas mediante avaliação pericial (Licença para Tratamento da Própria Saúde - artigos. 202, 203, 204; e a Licença por Acidente em Serviço - artigos 211 e 212) (BRASIL, 2017). Os dados coletados se referem à quantidade de dias de afastamento do trabalho por um período de 12 meses, nos anos de 2016, 2017 e 2018, para analisar o impacto de determinadas doenças no absenteísmo nessa universidade. Após o tratamento dos dados, o foco de análise girou em torno das doenças que podem ser provocadas ou agravadas por fatores existentes no ambiente de trabalho.

De acordo com a diretrizes e normas regulamentadoras de pesquisas envolvendo seres humanos, "as informações produzidas pelo sistema informatizado SIAPE SAÚDE poderão ser objeto de estudo e divulgação pela Administração Pública Federal, observadas as restrições referentes aos dados de caráter sigiloso e/ou pessoal" (BRASIL, 2017, p. 3).

Os dados individuais de cada prontuário eletrônico armazenado no SIAPENET do servidor periciado foram coletados por uma das autoras, na qualidade de médica perita oficial da UFRPE, especificamente dentro dos campos de anamnese clínica, conclusão pericial e CID. Depois foram, primeiramente, transferidos para o Microsoft Excel e nele processados para sua limpeza e organização. No que diz respeito às análises estatísticas, utilizou-se o software SPSS Statistics v.20. Os gráficos e visualizações foram feitos com uso do Microsoft Excel e Gephi v. 0.9.2.

A criação do plano de ações de vigilância e promoção seguiu o método $5 \mathrm{~W} 2 \mathrm{H}$, formado pelas iniciais, em inglês, de sete questões que abrangem praticamente todos os aspectos ligados a uma atividade (MEIRA, 2003). São elas: What (O que será feito?); Why (Por que será feito?); Where (Onde será feito?); When (Quando será feito?); Who (Por quem será feito?); How (Como será feito?); How much (Quanto vai custar?). Conquanto aqui se apresentem apenas algumas das respostas às perguntas propostas, é preciso estar atento, pois, se alguma das questões deixa de ser respondida, podem ocorrer empecilhos para a conquista do resultado esperado do processo.

\section{RESULTADOS E DISCUSSÃO}

\section{Perfil de morbidade dos servidores públicos periciados}

As 1.232 perícias em saúde realizadas ao longo do período 2016-2018 correspondem a 381 servidores periciados. A distribuição temporal das perícias apontou 296 em 2016; 404 em 2017; e 532 em 2018. Resulta interessante o crescimento que se manifesta no número de perícias de um ano para outro, sendo de $36 \%$ em 2017 com relação a 2016, bem como de 31\% em 2018 com relação a 2017. A Figura 1 mostra que o número de servidores periciados também aumentou, o que significa que mais pessoas estavam adoecendo, embora os casos recorrentes permanecessem constantes em 2016 e 2017, aumentando unicamente em 2018. 


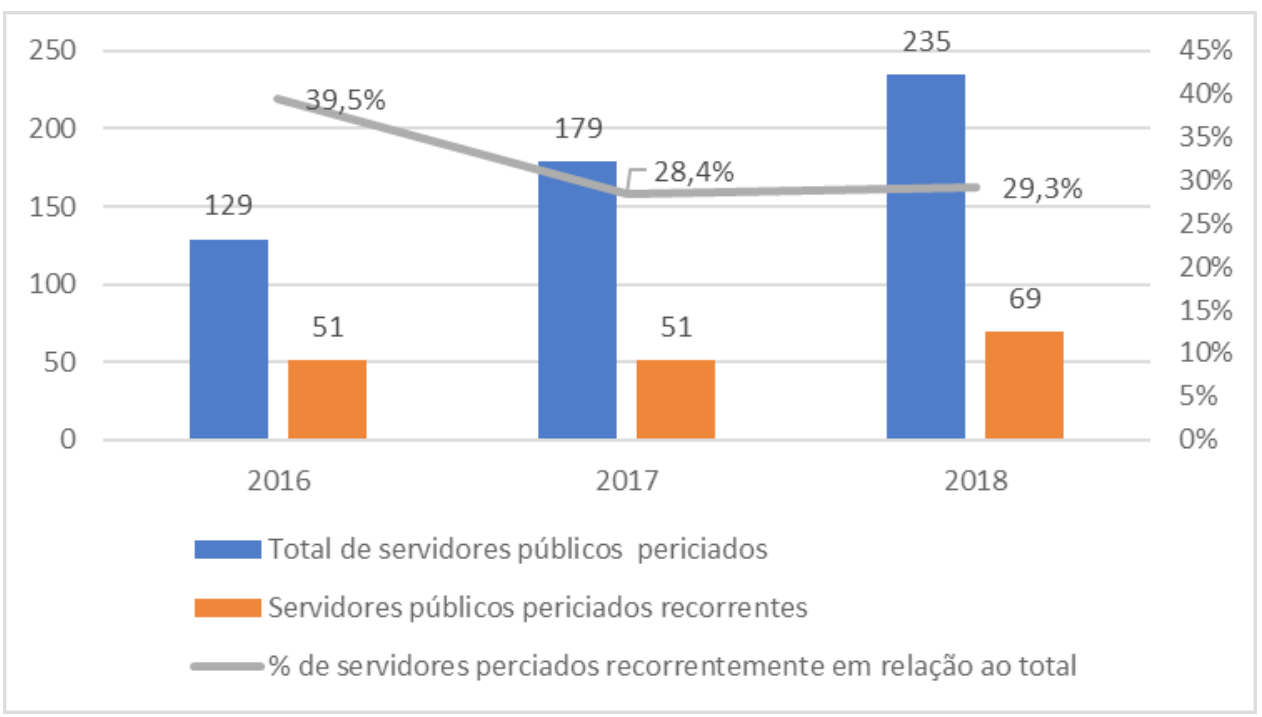

Figura 1 - Relação entre o total de servidores públicos periciados na UFRPE e periciados recorrentes (2016-2018) Fonte: elaboração das autoras.

Em relação à distribuição dos servidores periciados por sexo, a predominância é dos pertencentes ao sexo feminino ( $n=254 ; 67 \%$ ), enquanto os do sexo masculino compreendem 126 (33\%), resultado semelhante aos valores encontrados nas estatísticas apresentados por Santi, Barbiere e Cheade (2018) em seus estudos sobre o absenteísmo devido à doença no serviço público.

Os 381 servidores públicos periciados se distribuem numa faixa etária entre os 21-73 anos, a maior parte deles concentrando-se nas faixas entre os $31-40$ anos ( $n=137 ; 36 \%)$, e $51-60$ anos ( $n=86 ; 22 \%$ ) (Figura 2). A idade média é de 45,4 anos, especificamente, 44,5 anos no caso dos que pertencem ao sexo feminino e 47,3 anos ao masculino. A pesquisa de Santi, Barbiere e Cheade (2018) concluiu que a população feminina acima de 40 anos adoece mais e as causas são as doenças degenerativas e próprias da idade. Mas, diferentemente do que foi descrito por esses autores, na UFRPE, constatou-se um adoecimento maior na faixa etária entre 31 e 40 anos de idade, em ambos os sexos, e em pessoas com até 10 anos de serviço público (Figura 2).

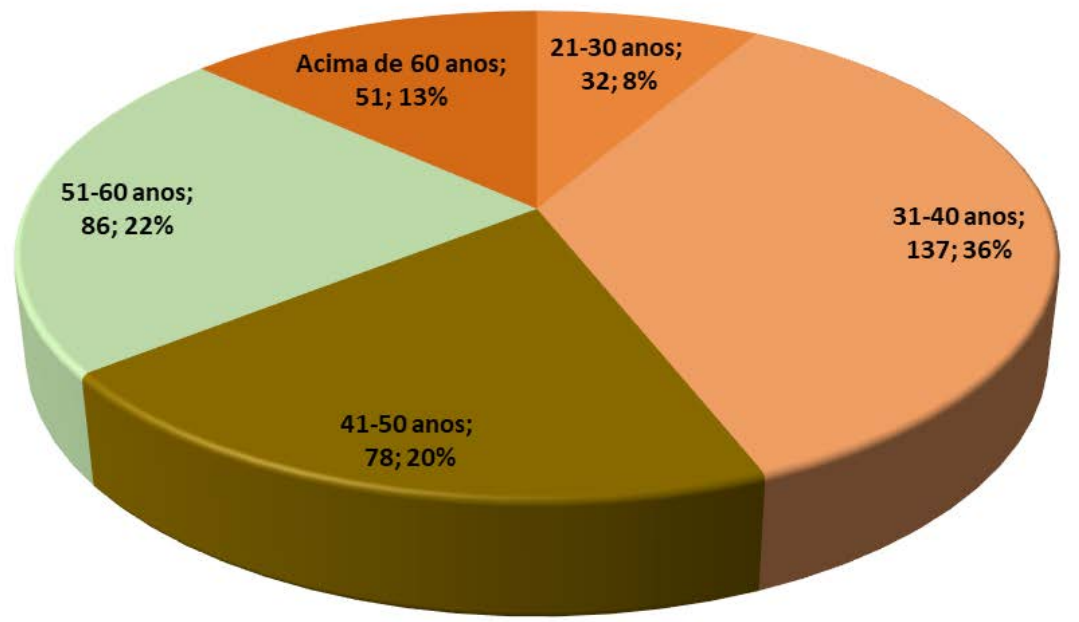

Figura 2 - Distribuição dos servidores públicos periciados por faixa etária Fonte: Krolls (2020, p. 57). 
Do total de 381 servidores periciados, 65\% $(\mathrm{n}=249)$ tinham um tempo de serviço entre 1 e 10 anos. A quantidade de servidores periciados diminui significativamente quando o tempo de serviço é superior aos 10 anos (Figura 3).

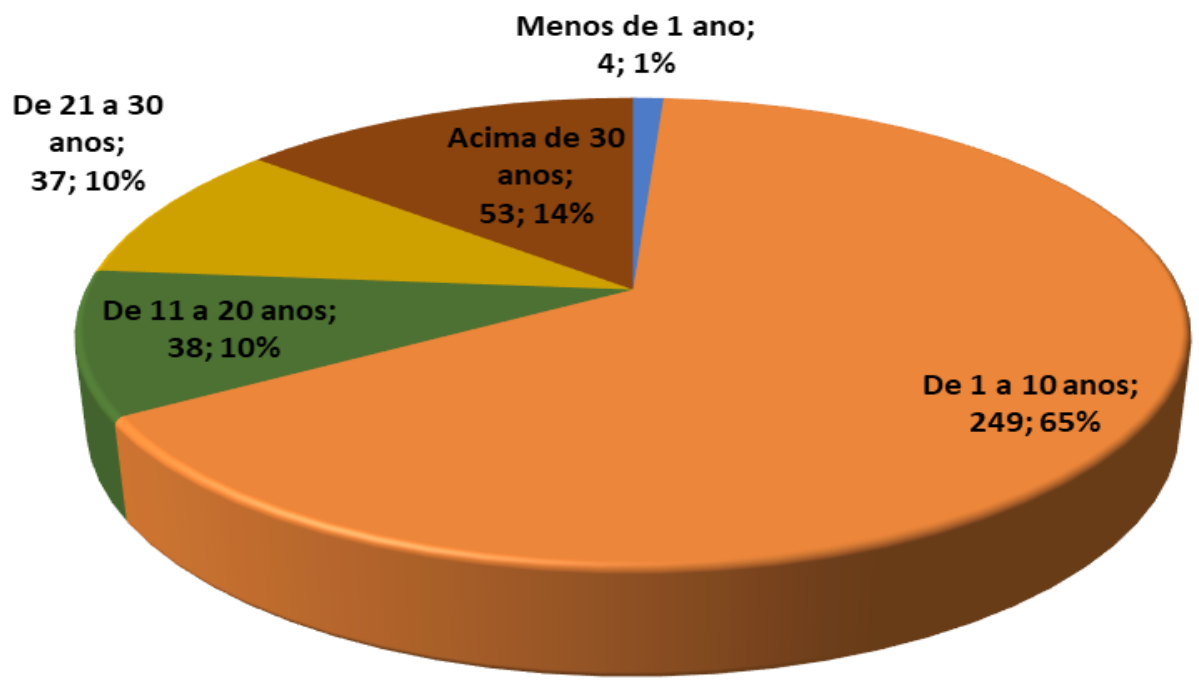

Figura 3 - Distribuição dos servidores públicos periciados e tempo serviço

Fonte: Krolls (2020, p. 58).

Na distribuição dos servidores periciados por cargos, destacam-se os docentes ( $n=156 ; 41 \%)$, seguidos pelos assistentes em administração ( $\mathrm{n}=65 ; 17 \%)$. Deve ser esclarecido que na UFRPE existem 1.200 docentes e 1.000 técnicos administrativos (essa segunda categoria engloba todas as outras categorias que não sejam docentes).

A partir das 1.232 perícias médicas realizadas, analisou-se a relação entre os problemas de saúde identificados e os cargos dos servidores periciados, complementando com as variáveis sexo, risco ao qual trabalhadores estavam expostos, o tipo e os dias de licença que receberam em cada caso.

Para analisar os grupos de doenças que mais impactaram nos servidores públicos, utilizou-se a Classificação Estatística Internacional de Doenças e Problemas relacionados à Saúde - CID10 (OMS,1997). O total de perícias se distribuiu em 20 grupos diferentes de doenças. Como é possível apreciar na Figura 4, destacam-se (acima de 50 ocorrências) as doenças relacionadas com os grupos Z ( $\mathrm{n}=205,17 \%) ; \mathrm{F}$ ( $\mathrm{n}=197$,

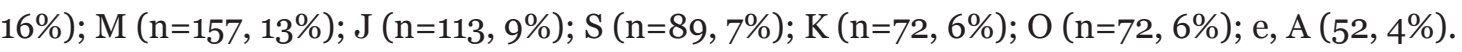

A principal causa de perícia corresponde à classificação CID Z54.o. - Convalescença pós-cirúrgica $(n=185)$, a qual representa $90 \%$ do total de perícias dentro do grupo $\mathrm{Z}$ e quase $16 \%$ com respeito a todas as perícias. Dentro desse grupo, as causas mais frequentes de perícias são as colelitíases (pedras na vesícula) e a catarata senil (afecção do aparelho ocular). Essas causas cirúrgicas não têm relação com os ambientes laborais.

Um resultado notável é o número de Transtornos Mentais e Comportamentais (doenças do grupo F no CID 10) que manifestaram os servidores públicos periciados da universidade em questão, no período analisado. No total, foram 197 perícias relacionadas com esse tipo de doenças, destacando-se aquelas vinculadas com os grupos F41.2 - Transtorno misto ansioso depressivo (n=23; 12\%), F32.2 - Episódio depressivo sem sintomas psicóticos ( $\mathrm{n}=20 ; 10 \%)$ e F32.0 - Episódios depressivos (n=18; 9\%), F33.1 - Transtorno depressivo recorrente $(15 ; 1,3 \%)$ e F43. - Reações ao stress grave e transtornos de adaptação ( $\mathrm{n}=14 ; 14,7 \%)$. 
Seguem-se outras doenças classificadas como Ao9 - Diarreia e gastroenterite de origem infecciosa presumível (n=22; 1,8\%), B34.9 - Infecção viral não especificada (n=20; 1,6\%), M54.4 - Lumbago com ciática ( $\mathrm{n}=17 ; 1,4 \%)$ e O20.0 - Hemorragia do início da gravidez (n=15; 1,3\%).

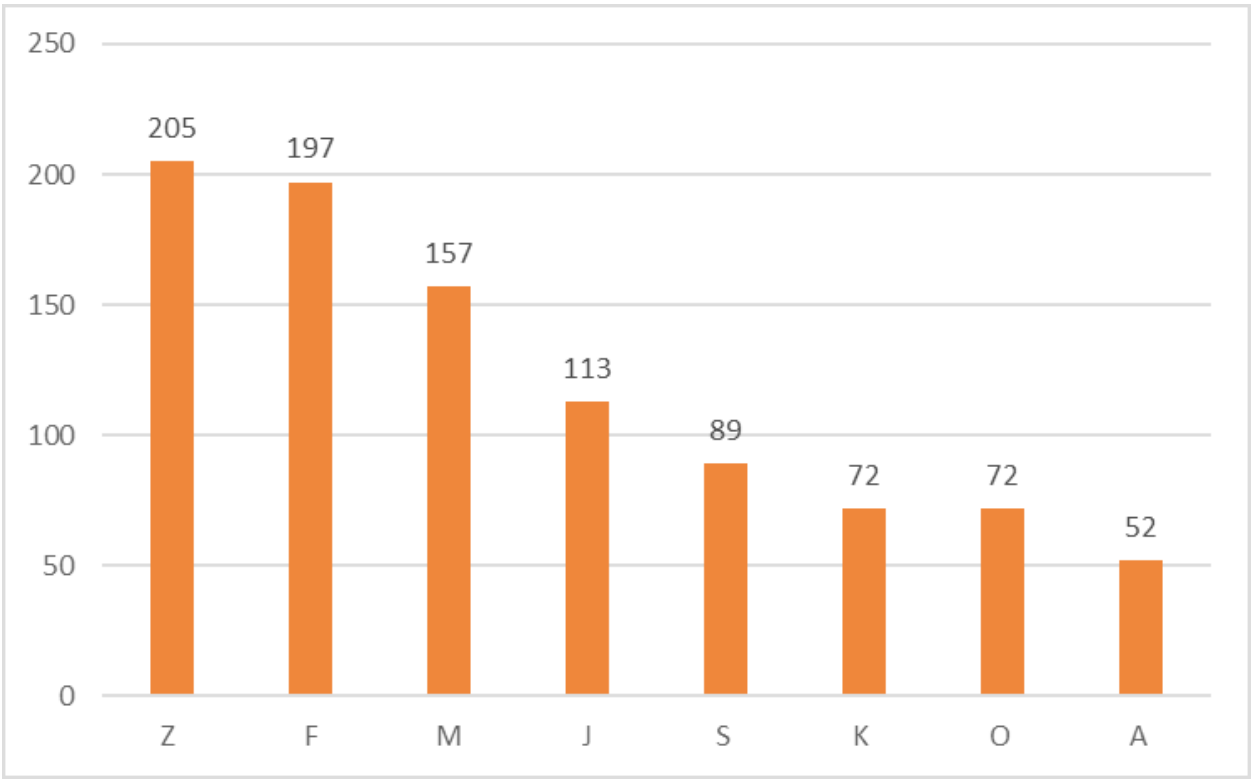

Figura 4 - Distribuição do número de perícias pelos grupos de doenças Fonte: Krolls (2020).

Observa-se o predomínio do sexo feminino nos cargos mais impactados, destacando-se a Z54.o Convalescença pós-cirúrgica, em que 70,7\% dos docentes adoecidos e 75\% dos assistentes de administração adoecidos eram mulheres. O sexo masculino mostrou um claro predomínio na F41.2 - Transtorno misto ansioso depressivo ( $75 \%$ dos docentes com adoecimento psíquico/mental).

Nesta fase de análise, partiu-se da hipótese de que poderia existir uma associação entre as morbidades e os cargos dos servidores públicos periciados. As 1.232 perícias em saúde foram realizadas em servidores que ocupavam 50 cargos diferentes. A visualização dessa relação é apresentada na Figura 5, elaborada por meio do software Gephi v. o.9.2. O tamanho do nodo, do rótulo e o gradiente de cor são proporcionais à quantidade de doenças ou problemas de saúde que se manifestaram por cargos, ou seja, à medida que uma morbidade apresenta maior frequência de ocorrência sobre determinado cargo, o tamanho desses elementos no gráfico aumenta. A espessura das arestas representa o grau de relação entre a variável grupo de doença e o cargo do servidor.

Foi identificado que, depois das convalescenças pós-cirúrgicas (Z54.o), as doenças dos grupos F41.2 Transtorno misto ansioso depressivo e F32 - Episódios depressivos foram as mais frequentes nos docentes (80\% dos docentes doentes). Já os transtornos osteomusculares como M54.4 - Dorsalgias foram mais frequentes em assistentes de administração doentes (23,5\%). 


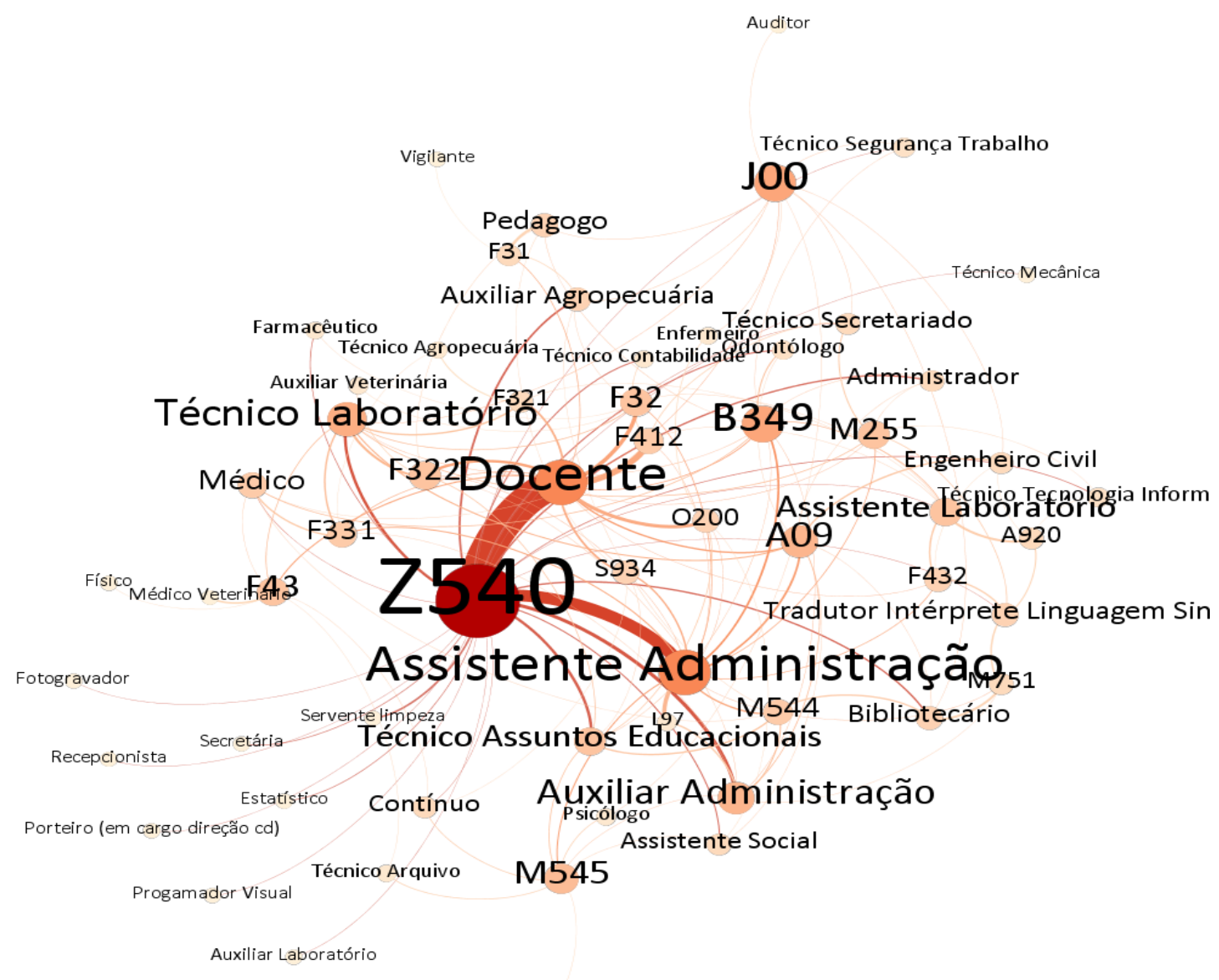

Nutricionista

Figura 5 - Relação entre a quantidade de perícias segundo o grupo de doença e o cargo dos servidores periciados Fonte: Krolls (2020, p. 62).

Com relação ao tempo de serviço, a Figura 6 representa que os servidores mais impactados com adoecimento pertenciam à faixa entre 1-10 anos de serviço público e as doenças mais frequentes foram Z54.0. - Convalescenças pós-cirúrgicas; F41.2 - Transtorno misto ansioso depressivo; F32.2 - Episódio depressivo grave sem sintomas psicóticos e A09.2 - Diarreia e gastroenterite de origem infecciosa presumível. Nos outros subgrupos também se repetem como mais frequentes os adoecimentos relacionados a procedimentos cirúrgicos, e logo depois as doenças do grupo F. 


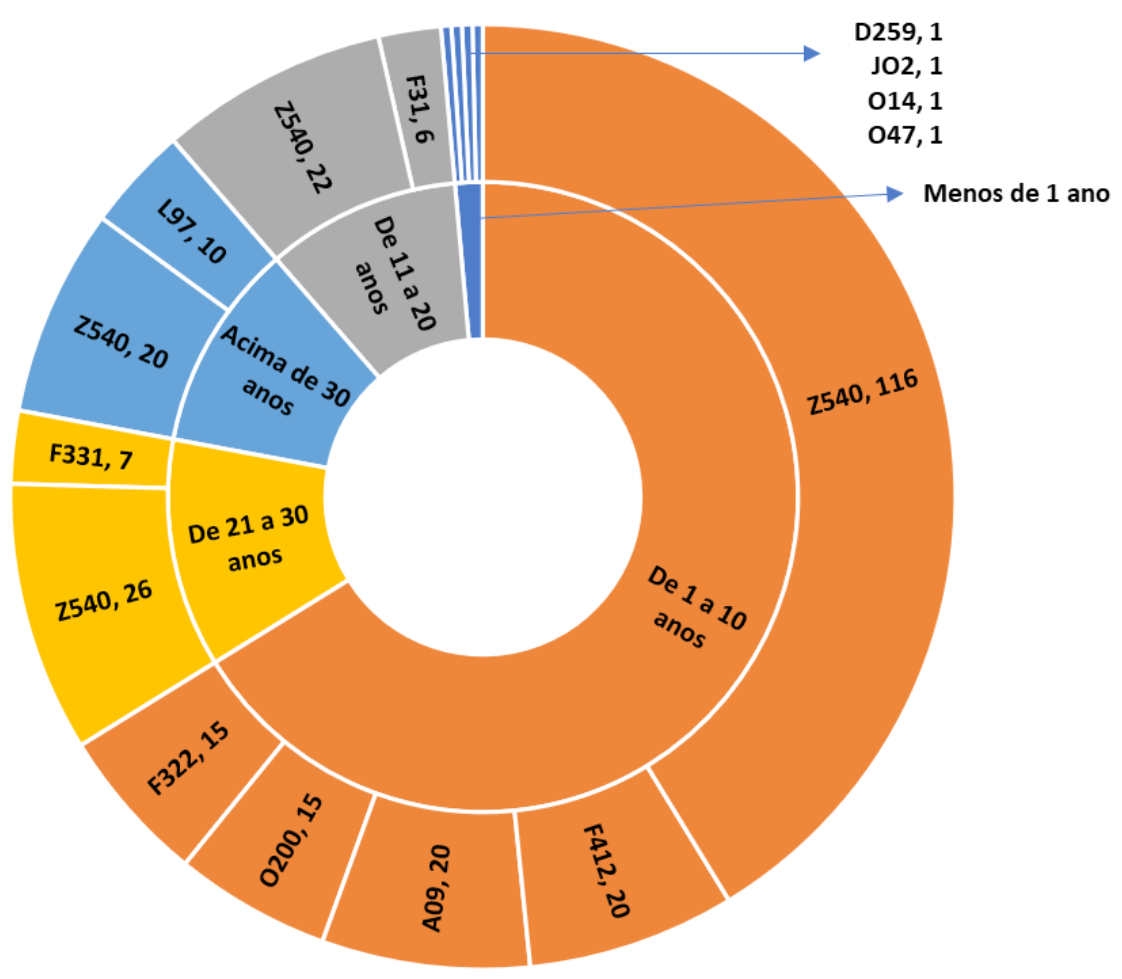

Figura 6 - Grupos de doenças mais frequentes por faixa de tempo de serviço Fonte: Krolls (2020, p. 63).

Uma outra informação analisada neste estudo foi a relação entre as doenças e os cargos, a partir de sua classificação segundo o risco para a saúde. Os cargos podem estar classificados quanto aos riscos Biológico, Ergonômico, Biológico/Ergonômico, Biológico/Radiação, Químico ou Físico, ou sem risco. A maioria dos cargos da universidade estudada é de natureza administrativa, burocrática e de docência, sem exposição a riscos específicos no ambiente de trabalho, segundo a categorização da norma regulamentadora $\mathrm{N}^{\circ} 15$ do Ministério do Trabalho e Emprego, relativa às Atividades e Operações Insalubres (BRASIL,1978). Contudo, é necessário esclarecer que esses postos de trabalho ainda não foram mapeados quanto à existência de outros fatores de riscos no ambiente de trabalho.

Dos 381 servidores públicos que passaram por perícia médica no período estudado, $316(82,9 \%)$ desempenhavam cargos para os quais não se identifica nenhum risco, enquanto 65 (17,1\%) estavam em cargos categorizados como sujeitos a algum tipo de risco: Biológico (27; 7,1\%); Ergonômico (17; 4,5\%); Biológico/Ergonômico (15; 3,9); Químico (15; 3,9\%); Biológico/Químico (3; o,8\%); Biológico/Radiação (1; o,3\%); e Físico (1; 0,3\%).

Portanto, a maior parte das perícias (932; 75,6\%) esteve associada a doenças em servidores de cargos que não os expunham a situações de risco, segundo a referida norma. O resto das perícias se realizou para doenças em servidores de cargos que estavam categorizados com algum tipo de risco, destacando aqueles com probabilidade de risco biológico, ou seja, exposição laboral ou contato com vírus, bactérias, parasitas, protozoários, fungos, entre outros (108 perícias; 8,8\%); ergonômico, provocado por fatores diversos que podem interferir nas características psicofisiológicas do trabalhador, causando desconforto ou afetando sua saúde (84 perícias; 6,8\%), biológico/ergonômico ( 57 perícias; 4,6\%) e riscos químicos, enquadrados como exposição laboral ou contato com substâncias químicas prejudiciais à saúde acima dos limites de tolerância biológica prescrita em norma (40 perícias; 3,2\%) (Tabela 1).

No caso de risco ergonômico, o maior impacto foi para os tradutores intérpretes de língua de sinais que, a partir da política nacional de inclusão educacional de alunos surdos, ganharam um relativo espaço. 
Pelas condições ou métodos de trabalho, é exigido desse grupo de profissionais esforços físicos repetitivos, concentração, atenção permanente e execução de tarefas desempenhadas em níveis acima dos limites de tolerância fixados, em razão da natureza e da intensidade do trabalho a que estão submetidos.

Tabela 1-Distribuição das perícias em saúde, segundo cargos com riscos

\begin{tabular}{|c|c|c|c|c|}
\hline Riscos & $\begin{array}{l}\text { Total de } \\
\text { Ocorrências }\end{array}$ & Cargos mais impactados & $\begin{array}{l}\text { Ocorrências segundo } \\
\text { o cargo }\end{array}$ & $\%$ \\
\hline \multirow[t]{2}{*}{ Biológico } & 108 & Médico & 43 & 39,8 \\
\hline & & Docente & 16 & 14,8 \\
\hline \multirow[t]{3}{*}{ Ergonômico } & 84 & $\begin{array}{c}\text { Tradutor Intérprete de Língua } \\
\text { de Sinais }\end{array}$ & 41 & 48,8 \\
\hline & & Técnico Agropecuária & 10 & 11,9 \\
\hline & & Técnico Laboratório & 9 & 10,7 \\
\hline \multirow[t]{4}{*}{ Biológico/Ergonômico } & 57 & Assistente Laboratório & 17 & 29,8 \\
\hline & & Auxiliar Agropecuária & 13 & 22,8 \\
\hline & & Técnico Laboratório & 11 & 19,3 \\
\hline & & Docente & 6 & 10,5 \\
\hline \multirow[t]{2}{*}{ Químico } & 40 & Técnico Laboratório & 21 & 52,5 \\
\hline & & Docente & 13 & 22,5 \\
\hline
\end{tabular}

Fonte: Krolls (2020, p. 68).

Nos cargos associados a situações de risco biológico, ocorreram mais adoecimentos nos médicos edocentes das áreas de medicina veterinária, zootecnia e outras com risco biológico; porém, esses adoecimentos não estavam diretamente relacionados aos agentes biológicos (vírus, fungos e bactérias), mas, provavelmente, a fatores no ambiente de trabalho.

A pesquisa apontou que, entre os servidores de cargos apontados com risco biológico (profissionais de saúde e docentes), as doenças do grupo F - Transtornos mentais e comportamentais foram as mais frequentes. Isto é, esses profissionais não adoeceram de doenças físicas relacionadas ao risco biológico, mas de doenças psíquicas relacionadas à pressão e ao stress que, por sua vez, podem estar relacionadas ao trabalho com público, medo de contaminação, falta de equipamentos de proteção individual (EPI) adequados, falta de condições de trabalho, sobrecarga e pressão. Como tais profissionais lidam com público, sugere-se uma sobrecarga de fatores estressores no ambiente de trabalho que precisam ser estudados mais detalhadamente. Além desses obstáculos, também pode haver problemas de relacionamento entre os próprios servidores, tornando o ambiente de trabalho ainda mais desgastante, pois, segundo Clarke (2011), em um ambiente organizacional, seja qual for o posto ocupado, é possível encontrar todos os tipos de personalidades e comportamentos. $\mathrm{O}$ autor acrescenta que, em especial, as situações podem ser muito estressantes quando gestores buscam o poder e o controle mediante manipulação de seus subordinados.

Em relação aos docentes, sabe-se que vêm sofrendo grande pressão para submeter a sua produção científica ao controle e à avaliação constantes para acreditação acadêmica. Quase não importa mais se o que o docente faz é valioso, e sim que seja publicado em periódicos indexados (PATRUS; DANTAS; SHIGAK, 2015). Do ponto de vista desta reflexão, não podemos deixar de constatar o efeito negativo dessa abordagem na docência. O que é exigido deles e que faz com que sejam valorizados é sua produção visível e, obviamente, para isso, eles dedicam seus melhores esforços. Todo trabalhador deveria exercer suas funções 
laborativas compatível às condições humanas. No Brasil, é bastante comum o sistema de avaliação da pósgraduação exigir, desse segmento de servidores, produtividade em pesquisa superior às suas condições. A jornada laboral impacta diretamente a saúde dos trabalhadores, tanto física como mental (CARDOSO, 2009; ROSSO, 2008); não obstante, o ambiente de trabalho onde exercem suas atividades, muitas vezes está em desacordo com as normas de segurança ocupacional.

No total, os servidores afetados receberam 24.750 dias de licença, dos quais 24.575 corresponderam aos tratamentos de saúde; unicamente 175 dias foram resultado de outras licenças. Na Tabela 2 são apresentadas as licenças por tratamento de saúde considerando as doenças mais frequentes, bem como o total de dias de licença em cada caso e a quantidade de dias por ocorrência. Dos servidores expostos a riscos específicos, aqueles expostos a riscos biológicos e ergonômicos foram os que mais obtiveram licenças médicas (7,1\% e 4,5\% do total, respectivamente), com uma diferença significativa (quase o dobro) em relação aos outros grupos de risco. Essas informações evidenciam como o trabalho excessivo ou ininterrupto causa acentuado risco à saúde do trabalhador, além de prejuízos à produção.

Como mostra a Tabela 2, predominaram as licenças por tratamento de saúde, particularmente, na morbidade Z540 - Convalescença pós-cirúrgica (181 ocorrências), acumulando o maior número de dias de licença (4.401). No entanto, essa não foi a doença com a média mais alta de dias, pois tanto a F32.2 - Episódio depressivo grave (31 dias) e a F41.2 - Transtorno misto ansioso depressivo (28 dias) tiveram médias superiores, indicando que são problemas de saúde que demandam maior tempo de recuperação. No outro lado do espectro, Ao9 - Diarreias e gastroenterites e B34.9 - Infecção viral inespecífica apresentaram médias baixas de dias de licença por ocorrência (3 e 5 dias, respectivamente), indicando que se trata de problemas de saúde que não demandam um tempo de recuperação longo.

Tabela 2 - Distribuição das licenças por tratamento de saúde, por morbidade

\begin{tabular}{lcccc} 
Grupo de doenças & Ocorrências & Número de licenças & Dias de licença & $\begin{array}{c}\text { Dias de licença } \\
\text { X ocorrência }\end{array}$ \\
\hline Z540 & 184 & 181 & 4.401 & 24 \\
F412 & 23 & 23 & 646 & 28 \\
A09 & 22 & 22 & 61 & 3 \\
F322 & 20 & 20 & 628 & 31 \\
B349 & 20 & 20 & 100 & 5 \\
F32 & 18 & 18 & 420 & 23 \\
M544 & 17 & 17 & 174 & 10 \\
O200 & 15 & 15 & 308 & 21 \\
F331 & 15 & 15 & 326 & 22 \\
\hline
\end{tabular}

Fonte: Krolls (2020, p. 71).

Portanto, a partir do estudo feito, pode ser concluído que, desconsiderando-se aqui as causas de afastamento por patologias tratáveis cirurgicamente, cujo afastamento foi para convalescer após o tratamento cirúrgico e cujas causas são de natureza específica, não relacionada a fatores no ambiente de trabalho, fica-se frente a frente com uma população de servidores da qual a maioria das doenças que levaram ao afastamento do trabalho estão relacionadas com os grupos F. - Transtornos mentais e comportamentais e M. - Doenças osteomusculares. Servidores em cargos de docentes e assistentes administrativos foram, respectivamente, os mais acometidos pelas doenças antes citadas. Retomando a discussão sobre a situação 
dos docentes, o tempo dedicado às atividades costuma extrapolar, e muito, a jornada de trabalho normal. O tempo à disposição do trabalho deve considerar também aquele tempo em que o docente continua realizando o trabalho em casa, após finalizar sua jornada na universidade. Essa prática é facilitada pela difusão das novas tecnologias de informação e comunicação.

Adicionalmente, observa-se uma predominância de adoecimento nos servidores da faixa etária entre 31-40 anos e com um tempo de vida pública entre 1 e 10 anos, ao contrário do que seria de se esperar, ou seja, que a população acima de 40 anos apresentasse mais afastamentos por doenças, devido ao próprio processo degenerativo de envelhecimento e ao aparecimento de doenças cardiovasculares, endócrinas e osteomusculares. Contudo, o achado é explicável pela frequência de doenças do grupo $\mathrm{F}$, como já foi dito antes. Tais resultados são semelhantes aos obtidos por Oliveira, Baldacara e Maia (2015) em seu estudo realizado entre os servidores públicos federais no Tocantins, onde os transtornos mentais foram bastante expressivos. As doenças mais frequentes encontradas por esses autores foram reação aguda ao stress e transtorno de adaptação (CID F43), outros transtornos ansiosos (CID F41), transtornos de adaptação (CID F43.1) e episódios depressivos (CID F32).

Os resultados desta pesquisa sugerem que essa população de servidores, principalmente na faixa etária de 31-40 anos, está sendo exposta a fatores de risco no ambiente de trabalho. Igualmente sugerem que o Governo não oferece uma política de atendimento adequada e eficiente à saúde de seus servidores, especialmente, desse segmento de trabalhadores, que apresentam um elevado número de doenças profissionais, principalmente, psiquiátricas. Considera-se aqui a saúde, em sua dimensão ampliada, desde a promoção, a proteção até a recuperação, “como 'necessidade necessária' a ser suprida, a priori, pelo Estado brasileiro, em virtude de este trazer para si, constitucionalmente, a ação de saúde para todos como seu dever" (VASCONCELLOS; AGUIAR, 2017, p. 607). Também não se descarta que as conjunturas familiar e social externa podem contribuir para que adoeçam ou que piorem de patologia psíquica pré-existente, sendo um fator de agravamento. Os resultados apontam para a concepção já descrita por muitos pesquisadores, entre eles Raminger e Nardi (2007), Dejours (2008), Nardocci et al. (2013), que alertam que saúde mental/ psíquica e saúde do trabalho são indissociáveis na conjuntura produtiva atual, incluindo o serviço público.

\section{Proposta de ações de vigilância e promoção da saúde dos servidores da UFRPE}

A dimensão dos problemas identificados na pesquisa retrata e espelha situações e impõe variações na forma de enfrentá-los. Assim, a partir das evidências do perfil de risco e morbidade identificados, foi possível propor algumas ações de vigilância e promoção da saúde dos servidores da UFRPE. A reversão dos agravos decorrentes da relação entre saúde e trabalho depende da intervenção, por parte das estruturas de saúde pública, na sua vertente de vigilância em saúde. É somente por ela que se pode efetivamente transformar a realidade, intervindo nos processos, ambientes e condições de trabalho, como se lê no plano de ações do Quadro 1, elaborado mediante uma adaptação da ferramenta metodológica $5 \mathrm{~W} 2 \mathrm{H}$. 


\section{Quadro 1-Ações de vigilância e promoção da saúde dos servidores da UFRPE}

(continua)

\begin{tabular}{|c|c|c|c|}
\hline O que será feito? & Por quê? & Por quem? & $\begin{array}{l}\begin{array}{l}\text { Público-alvo } \\
\text { prioritário }\end{array} \\
\end{array}$ \\
\hline $\begin{array}{l}\text { Avaliar a adaptação dos } \\
\text { novos servidores no trabalho } \\
\text { e detectar problemas e } \\
\text { dificuldades enfrentados. Fazer } \\
\text { encaminhamento específico para } \\
\text { consulta com médico do trabalho } \\
\text { e outros especialistas (psiquiatra, } \\
\text { psicólogo). Se necessária, } \\
\text { avaliação contínua periódica. }\end{array}$ & $\begin{array}{l}\text { Alta incidência de transtornos } \\
\text { mentais e comportamentais }\end{array}$ & $\begin{array}{l}\text { Equipe de cargos e } \\
\text { salário da PROGEPE } \\
\text { e equipe de saúde } \\
\text { ocupacional - médico } \\
\text { do trabalho e } \\
\text { engenheiros e técnicos } \\
\text { de segurança do } \\
\text { trabalho }\end{array}$ & Docentes \\
\hline $\begin{array}{l}\text { Avaliação dos diferentes } \\
\text { departamentos acadêmicos, } \\
\text { com relatório e mapeamento } \\
\text { de problemas por psicólogos } \\
\text { organizacionais e assistentes } \\
\text { sociais. Elaboração de relatório } \\
\text { com sugestões para a alta direção } \\
\text { da universidade. }\end{array}$ & $\begin{array}{l}\text { Alta incidência de transtornos } \\
\text { mentais e comportamentais }\end{array}$ & $\begin{array}{l}\text { Psicólogos e } \\
\text { assistentes sociais do } \\
\text { DQV }\end{array}$ & Docentes \\
\hline $\begin{array}{l}\text { Capacitação dos servidores em } \\
\text { temas, tais como relacionamento } \\
\text { interpessoal, liderança e estímulo } \\
\text { ao desempenho. }\end{array}$ & $\begin{array}{l}\text { Alta incidência de transtornos } \\
\text { mentais e comportamentais }\end{array}$ & $\begin{array}{l}\text { Psicólogos da } \\
\text { PROGEPE e dos DQV } \\
\text { e, eventualmente. } \\
\text { profissionais externos } \\
\text { contratados }\end{array}$ & $\begin{array}{l}\text { Docentes } \\
\text { e técnicos } \\
\text { administrativos } \\
\text { em cargos que } \\
\text { exigem ações de } \\
\text { gestão de pessoas } \\
\text { e equipes } \\
\end{array}$ \\
\hline $\begin{array}{l}\text { Estudo ergonômico detalhado, } \\
\text { tanto do ambiente físico } \\
\text { (mobiliário e materiais), como } \\
\text { do processo de trabalho, visando } \\
\text { prevenir a sobrecarga física de } \\
\text { grupos musculares espećficos, } \\
\text { esforços repetitivos e pressão. }\end{array}$ & $\begin{array}{l}\text { Alta incidência de lesões } \\
\text { osteomusculares }\end{array}$ & $\begin{array}{l}\text { Equipe de engenheiros } \\
\text { e técnicos de } \\
\text { segurança do trabalho } \\
\text { e, eventualmente, } \\
\text { profissionais de } \\
\text { ergonomia externos } \\
\text { contratados }\end{array}$ & $\begin{array}{l}\text { Técnicos } \\
\text { administrativos }\end{array}$ \\
\hline $\begin{array}{l}\text { Implementar ginástica laboral } \\
\text { em todos os departamentos e } \\
\text { locais de trabalho como medida } \\
\text { preventiva de adoecimento } \\
\text { osteomuscular e doenças } \\
\text { osteomusculares relacionadas a } \\
\text { esforços repetitivos e pressão. }\end{array}$ & $\begin{array}{l}\text { Alta incidência de lesões } \\
\text { osteomusculares }\end{array}$ & $\begin{array}{l}\text { Parceria com } \\
\text { departamento de } \\
\text { educação física da } \\
\text { UFRPE ou com o SESI } \\
\text { ou contratação de } \\
\text { profissionais externos - } \\
\text { educador físico }\end{array}$ & $\begin{array}{l}\text { Técnicos } \\
\text { administrativos }\end{array}$ \\
\hline $\begin{array}{l}\text { Estudo anual do perfil } \\
\text { epidemiológico, a partir de exame } \\
\text { médico periódico, com cálculo } \\
\text { deíndice de massa corpórea } \\
\text { (IMC), pressão arterial, pulso, } \\
\text { glicemia,assim como dos dados } \\
\text { estatísticos de adoecimento. }\end{array}$ & $\begin{array}{l}\text { Subsidiar o planejamento } \\
\text { anual de ações específicas } \\
\text { para as doenças mais } \\
\text { frequentes: doenças } \\
\text { psíquicas e sofrimento } \\
\text { no trabalho e doenças } \\
\text { osteomusculares. }\end{array}$ & $\begin{array}{l}\text { Equipe médica } \\
\text { assistencial e } \\
\text { médico do trabalho. } \\
\text { Enfermeiros e técnicos } \\
\text { administrativos do DQV }\end{array}$ & $\begin{array}{l}\text { Docentes que } \\
\text { ingressaram na } \\
\text { UFRPE nos últimos } \\
10 \text { anos }\end{array}$ \\
\hline $\begin{array}{l}\text { Palestras e outros meios de } \\
\text { comunicação ativa e permanente } \\
\text { sobre a necessidade de } \\
\text { comunicação de acidentes e } \\
\text { doenças no trabalho. }\end{array}$ & Subnotificação & $\begin{array}{l}\text { Equipe de saúde e } \\
\text { segurança do trabalho: } \\
\text { médicos, engenheiros e } \\
\text { técnicos }\end{array}$ & Docentes \\
\hline
\end{tabular}


(conclusão)

\begin{tabular}{|l|l|l|l|}
\hline O que será feito? & Por quê? & Por quem? & $\begin{array}{l}\text { Público-alvo } \\
\text { prioritário }\end{array}$ \\
\hline $\begin{array}{l}\text { Realização dos exames médicos } \\
\text { periódicos dos servidores de } \\
\text { acordo com a periodicidade } \\
\text { exigida na legislação específica. }\end{array}$ & Vigilância da saúde & Médico do trabalho & $\begin{array}{l}\text { Todos os } \\
\text { servidores }\end{array}$ \\
\hline $\begin{array}{l}\text { Adequação dos ambientes de } \\
\text { trabalho com riscos específicos } \\
\text { (químicos, físicos e biológicos) } \\
\text { e a aquisição de equipamentos } \\
\text { de proteção coletiva (EPC) e de } \\
\text { proteção individual (EPI) bem } \\
\text { como de materiais de trabalho } \\
\text { no sentido de neutralizar ou } \\
\text { minimizar ao máximo esses riscos. }\end{array}$ & Prevenção de riscos & $\begin{array}{l}\text { Engenheiros e técnicos } \\
\text { de segurança do } \\
\text { trabalho e direção da } \\
\text { UFRPE e da PROGEPE }\end{array}$ & $\begin{array}{l}\text { Todos os } \\
\text { servidores com } \\
\text { riscos no ambiente } \\
\text { de trabalho }\end{array}$ \\
\hline $\begin{array}{l}\text { Novos estudos em adoecimento } \\
\text { psíquico e osteomuscular. }\end{array}$ & $\begin{array}{l}\text { Necessidade de melhor } \\
\text { elucidação dos fatores } \\
\text { determinantes do } \\
\text { adoecimento }\end{array}$ & $\begin{array}{l}\text { Peritos oficiais em } \\
\text { saúde }\end{array}$ & $\begin{array}{l}\text { Servidores } \\
\text { adoecidos }\end{array}$ \\
\hline
\end{tabular}

Fonte: elaboração das autoras.

A avaliação da capacidade laborativa dos servidores federais toma nova dimensão com o conceito de vigilância em saúde e busca aproximar a perícia da realidade e do cenário do mundo do trabalho no qual atua o servidor público federal. Portanto, a concepção que fundamenta o elenco das temáticas a serem trabalhadas relativo às ações de vigilância e promoção da saúde dos servidores da UFRPE prioriza ações voltadas para a educação em saúde (Quadro 1) e, como já evidenciou Carneiro (2011), se caracterizam por intervenções que reduzam os riscos ou agravos à saúde dos servidores.

Nessa perspectiva, as relações trabalho e saúde pressupõem participação dos servidores como sujeitos ativos e centrais na transformação dos processos de trabalho (MARTINS et al., 2017). O plano de ação busca proteger a saúde do trabalhador, prevenir doenças e acidentes, assegurar aos mesmos um ambiente onde exerçam suas atividades em condições dignas, por meio de orientações de saúde, higiene e segurança, que os tornem partícipes ativos da busca de sua própria saúde. Daí a importância das ações para elevar o conhecimento sobre saúde e seus cuidados, assim como o incentivo à realização de exames periódicos.

Cardoso e Morgado (2019) reforçam a importância das reflexões e investigações que aportem conhecimentos sobre os determinantes do processo de adoecimento no trabalho, ampliando a conscientização e a responsabilidade dos servidores no espaço micro das organizações, mas também das autoridades públicas no espaço macro, no qual se elaboram regras e legislações. Para os autores, reduzir o adoecimento e os acidentes vinculados ao trabalho não é suficiente se continuarmos a agir, prioritariamente, sobre suas consequências. São necessárias medidas preventivas para a construção de uma cultura de valorização da saúde de modo a reduzir a morbidade, por meio de hábitos saudáveis de vida e de trabalho, e de políticas públicas para materializar tudo isso em realidade. Se as esferas decisórias de gestão exigem apenas a notificação de agravos relacionados ao trabalho, sem exigências de intervenção sobre suas causas, Vasconcellos e Aguiar (2017) acreditam que fica inviabilizado o controle e prevenção desses agravos, perpetuando o ciclo de doenças dos trabalhadores. As ações de vigilância e promoção da saúde dos servidores (Quadro 1) são um exercício antecipado, visando evitar danos ou agravos à saúde do servidor decorrentes de fatores comportamentais e hábitos de vida, do ambiente e/ou do processo de trabalho. O principal desafio das ações de vigilância e promoção da saúde propostas é desenvolver ações 
articuladas de promoção da saúde do servidor, que alterem ambientes e processos de trabalho e produzam impactos positivos sobre a saúde dos servidores das universidades.

A Constituição Federal de 1988 introduziu uma moderna filosofia humanista, destacando à dignidade da pessoa humana como princípio fundamental. Este moderno pensamento simbolizou um novo movimento social inspirado em políticas mundiais de defesa de direitos humanos, impondo ao empregador, seja ele público ou privado, uma responsabilidade objetiva, que rompe, definitivamente, com conceitos tradicionais. Nesse sentido, o Estado tem a obrigação de assegurar, mediante ações públicas modernas e eficazes, a proteção da saúde de seus servidores, especialmente, aqueles em exercício de atividades que apresentam maiores riscos de acidentes e doenças profissionais. Não se trata de uma conjectura, mas de uma obrigação.

Apesar da garantia constitucional ao direito da saúde dos trabalhadores, de nada adiantaria se não fossem criados mecanismos para a viabilização dessas garantias. Sem dúvida, esse é o grande problema para a efetivação dos direitos dos servidores públicos expostos a riscos específicos no ambiente de trabalho. Porém, há que se entender também como a atividade de trabalho é realizada e, além disso, conhecer detalhadamente a gestão, a organização, as condições e as relações de trabalho em cada setor nas organizações. Isso pressupõe "conhecer como os indivíduos enfrentam os riscos, as doenças e os acidentes relacionados ao trabalho." (CARDOSO; MORGADO, 2019, p. 170).

Vasconcellos e Oliveira (2011, p. 40) entendem que a saúde do trabalhador "invoca o direito à saúde no seu espectro irrestrito de cidadania plena”. É nesta condição de cidadania plena que o campo da saúde do trabalhador se constitui na vinculação permanente entre ação de saúde e ação política com os trabalhadores de organizações públicas ou privadas, como "sujeitos e protagonistas da ação político-institucional, inclusive na construção de conhecimentos e dos instrumentos de intervenção" (VASCONCELLOS; OLIVEIRA, 2011, p. 40).

\section{CONSIDERAÇÕES FINAIS}

O objetivo geral do estudo aqui apresentado foi propor ações de vigilância e promoção da saúde para prevenir principais riscos no ambiente de trabalho dos servidores da UFRPE, a partir do uso de informações registradas no módulo Perícia em Saúde do SIASS. Até então, essas informações ficavam armazenadas e não eram utilizadas para subsidiar ações nem políticas de saúde. Neste sentido, as informações sobre a saúde dos servidores revelaram suas potencialidades, pois permitiram identificar problemas e propor a tomada de decisões gerenciais em prol da prevenção e melhoria da saúde dos servidores.

As análises realizadas a partir do SIASS proporcionaram identificar que a UFRPE apresenta um crescimento no número de servidores que estão adoecendo. Uma parte desses servidores passou por diversos episódios de afastamento e prolongamento do afastamento do trabalho pelo mesmo tipo de doença, resultando no aumento das taxas de absenteísmo. Identificou-se que foram os transtornos mentais e comportamentais e, em seguida, os distúrbios osteomusculares as doenças mais comuns entre aquelas que levaram a afastamentos prolongados. Os docentes e assistentes administrativos foram os mais atingidos, respectivamente. Verificou-se também que, em relação ao número de ocorrências de licenças médicas, os servidores expostos a riscos biológicos, ergonômicos, biológicos/ergonômicos foram os que tiveram a maior frequência de adoecimento, em comparação com as pessoas expostas a outros riscos ocupacionais, como químicos e físicos.

As categorias profissionais mais impactadas foram as dos docentes, médicos, tradutores intérpretes de línguas de sinais, técnicos e assistentes de laboratório. No grupo sem riscos ocupacionais específicos, destacam-se os técnicos e assistentes em administração, com maior adoecimento osteomuscular. Com relação aos profissionais da saúde e docentes, cujos cargos estão categorizados como de risco biológico, é preciso dizer que pode haver riscos ergonômicos ou outros tipos de riscos que ainda não tenham sido mapeados pela equipe de segurança e saúde do trabalho e necessitem de investigação. Suspeita-se que haja 
uma sobrecarga emocional e física sobre esses profissionais que lidam com o público, atendem pessoas, ensinam em sala de aula ou realizam processos intensos de pesquisas complexas que precisa ser mais bem investigada.

Os resultados apontam para caminhos a serem seguidos, focando as ações de vigilância e promoção de saúde no ambiente de trabalho. Recomenda-se aos gestores da UFRPE especial atenção à saúde dos servidores com risco ergonômico, para que adequações sejam feitas a partir dos laudos ergonômicos dos seus diversos ambientes, emitidos pela equipe de engenharia de segurança do trabalho que faz parte da equipe SIASS, com vistas a prevenir fatores agravantes e patologias osteomusculares presentes no ambiente e nos processos de trabalho. Também é necessária a avaliação periódica da adaptação dos servidores, com encaminhamento a médicos e psicólogos e acompanhamento por estes, se for preciso. Mediante uma anamnese ocupacional detalhada, o perito indagar, por exemplo, como é realizado o trabalho, se existe sobrecarga, se os prazos e cobranças de produtividade são suportáveis, se o relacionamento com a chefia e com os colegas é bom, pois todos esses fatores podem influenciar a saúde do trabalhador ou mesmo causar danos a ela.

Durante a pesquisa se identificaram algumas limitações relacionadas com o sistema de informação do SIASS, que correspondem a alguns dos problemas identificados na revisão de literatura feita por Kruse et al. (2018) a respeito da implantação de prontuários eletrônicos. Primeiramente, se detectou que os prontuários médicos contidos no SIAPE SAÚDE nem sempre estavam completamente preenchidos. Por exemplo, identificou-se a falta de detalhamento do processo de trabalho e dos riscos ocupacionais, ou seja, dados incompletos na anamnese ocupacional dos pacientes periciados. A descrição dos riscos de exposição não estava presente nos prontuários e teve que ser pesquisada nas tabelas de servidores expostos a riscos ocupacionais, elaboradas pela equipe de engenharia e medicina do trabalho da UFRPE, disponíveis para fins de concessão de adicionais de insalubridade e periculosidade. Apesar do treinamento pericial realizado por todos os profissionais, a anamnese ocupacional precisa ser mais bem explorada, uma vez que, a partir dela, é possível fazer diagnósticos precoces de doenças ocupacionais. Recomenda-se, portanto, novo treinamento da equipe para melhor investigação epidemiológica dos agravos suspeitos relacionados com a especificidade do trabalho.

Quanto a isso, identificou-se também que a maioria dos cargos não tinha sido mapeada para outros riscos como, por exemplo, riscos ergonômicos, incluindo riscos psicossociais e cognitivos. Portanto, se faz preciso um mapeamento completo dos cargos da UFRPE.

Finalmente, apesar da importância do uso da informação das perícias médicas para ações de vigilância e promoção de saúde, deve-se estar ciente de que, aqui, estamos trabalhando com um diagnóstico tardio, uma vez que os dados obtidos foram coletados de pessoas já adoecidas com necessidade de afastamento médico. O ideal é a prevenção de agravos à saúde em fases iniciais, antes que as patologias se agravem a ponto de causar incapacidade laboral e mais sofrimento aos pacientes. Portanto, o módulo do SIAPE SAÚDE de registro dos exames médicos periódicos deveria ser a principal fonte de informações para obtenção de dados de saúde e de adoecimento precoces, de modo a subsidiar ações preventivas por parte da gestão pública.

Todavia, apesar das informações relevantes explicitadas, ainda não informam sobre como a remuneração, a jornada de trabalho ou as demais condições laborais influenciaram no adoecimento desses trabalhadores. Uma vez que o diagnóstico por si só não possibilita a compreensão da relação entre trabalho e saúde dos trabalhadores, também não contribui, por sua vez, para que se tenha conhecimentos sobre os determinantes e causas do processo de adoecimento. Esta é a limitação do estudo apresentado neste artigo e, ao mesmo tempo, é uma indicação para novas pesquisas. 
Reciis - Revista Eletrônica de Comunicação, Informação \& Inovação em Saúde, Rio de Janeiro, v. 15, n. 3, p. 680-702, jul.-set. 2021 [www.reciis.icict.fiocruz.br] e-ISSN 1981-6278

\section{REFERÊNCIAS}

BERLINGUER, Giovanni. A doença. São Paulo: Cebes; Hucitec, 1988.

BRASIL. Ministério da Saúde. Portaria nº 2.293 de 23 de outubro de 2014. Institui as diretrizes de atenção à saúde dos servidores públicos do Ministério da Saúde. Diário Oficial da União, Brasília, DF, 23 out. 2014. Disponível em: http://bvsms.saude.gov.br/bvs/saudelegis/gm/2014/prt2293_23 10_2014. html. Acesso em: 11 de mar. 2021.

BRASIL. Ministério do Planejamento, Desenvolvimento e Gestão. Secretaria de Gestão de Pessoas e Relações do Trabalho no Serviço Público. Manual de Perícia Oficial em Saúde do Servidor Público Federal. 3. ed. rev. Brasília: DF, 2017. 147 p. Disponível em: http://www.jandaiadosul.ufpr.br/wp-content/ uploads/2017/07/MANUAL-DE-PERICIA-OFICIAL-EM-SAUDE-DO-SERVIDOR-PUBLICO-FEDERAL-3AEDICAO-ANO-2017-VERSAO-28ABR2017.pdf Acesso em: 01 de jul. 2021.

BRASIL. Ministério do Planejamento, Orçamento e Gestão. Secretaria de Recursos Humanos. Política Nacional de Atenção à Saúde do Servidor Público Federal: uma construção coletiva. Brasília, DF, 2008. Disponível em: http://www.uff.br/sites/default/files/servicos/legislacao/poltica_de_aten_o_siass.pdf. Acesso em: 11 mar. 2021.

BRASIL. Ministério do Planejamento, Orçamento e Gestão. Secretaria de Recursos Humanos. Portaria Normativa $n^{\circ} 3$ de 25 de março de 2013. Institui as diretrizes gerais de promoção da saúde do servidor público federal, que visam orientar os órgãos e entidades do Sistema de Pessoal Civil da Administração Federal - SIPEC. Diário Oficial da União, Brasília, DF, 27 mar. 2013. Seção 1, p. 77. Disponível em: https://www.lexml.gov.br/urn/urn:lex:br:ministerio.planejamento.orcamento.gestao;secretaria.gestao. publica:portaria.normativa:2013-03-25;3. Acesso em: 11 mar. 2021.

BRASIL. Ministério do Trabalho e Emprego. Norma Regulamentadora No. 15 (NR-15): atividades e operações insalubres. Diário Oficial da União, Brasília, DF, 6 jul 1978. Disponível em: https://www. legisweb.com.br/legislacao/?id=248616. Acesso em: 1 jul. 2021.

BRASIL. Presidência da República. Decreto $n^{\circ} 6.833$ de 29 de abril de 2009. Institui o Subsistema Integrado de Atenção à Saúde do Servidor Público Federal - SIASS e o Comitê Gestor de Atenção à Saúde do Servidor. Diário Oficial da União, Brasília, DF, 30 abr 2009. Disponível em: http://www. planalto.gov.br/ccivil_03/_Ato2007-2010/2009/Decreto/D6833.htm Acesso em: 11 mar. 2021.

BRASIL. Presidência da República. Lei nº 8.080 de 19 de setembro de 1990. Dispõe sobre as condições para a promoção, proteção e recuperação da saúde, a organização e o funcionamento dos serviços correspondentes e dá outras providências. Diário Oficial da União, Brasília, DF, 20 set. 1990. Disponível em: http://conselho.saude.gov.br/legislacao/lei8080_190990.htm. Acesso em: 11 mar. 2021.

CARDOSO, Ana Claudia Moreira; MORGADO, Luciana. Trabalho e saúde do trabalhador no contexto atual: ensinamentos da Enquete Europeia sobre Condições de Trabalho. Saúde e Sociedade, São Paulo, v. 28, n.1, p.169-181, 2019. Disponível em: http://dx.doi.org/10.1590/s0104-12902019170507. Acesso em: 21 fev. 2021.

CARDOSO, Ana Claudia Moreira. Tempos de trabalho, tempos de não trabalho. São Paulo: Annablume, 2009.

CARNEIRO, Isabel Magda Said Pierre. A especificidade do trabalho pedagógico: a atuação de profissionais de pedagogia na Organização Não Governamental Comunicação e Cultura. Revista Metáfora Educacional, Feira de Santana, n. 10, p. 107-119, jun. 2011. Disponível em: http://www. valdeci.bio.br/pdf/Carneiro A ESPECIFICIDADE DO.pdf. Acesso em: 21 fev. 2021.

CLARKE, John. Trabalhando com monstros: como identificar psicopatas no seu trabalho e como se proteger deles. São Paulo: Fundamento, 2011.

DEJOURS, Christophe. A loucura do trabalho: estudo de psicopatologia do trabalho. 5. ed. São Paulo: Oboré, 2012.

FISCHER, Frida Marina; MORENO, Claudia Roberta de Castro; ROTENBERG, Lúcia. Trabalho em turnos e noturno na sociedade 24 horas. São Paulo: Atheneu, 2003. 
KROLLS, Tirze Barbalho. Perícia médica como recurso informacional na vigilância em saúde do servidor público federal e na gestão pública. 2020. 96 f. Dissertação (Mestrado em Gestão Pública). - Universidade Federal de Pernambuco, Recife, 2020.

KRUSE, Clemens Scott; STEIN, Anna; THOMAS, Heather; KAUR, Harmander. The use of electronic health records to support population health: a systematic review of the literature. Journal of Medical Systems, Nova lorque, v. 42, n. 11, p. 214, 2018. DOI: https://dx.doi.org/10.1007\%2Fs10916-018-1075-6. Disponível em: https://www.ncbi.nlm.nih.gov/pmc/articles/PMC6182727/ Acesso em: 10 mar. 2021.

MARTINS, Maria Inês Carsalade et al. A política de atenção à saúde do servidor público federal no Brasil: atores, trajetórias e desafios. Ciência \& Saúde Coletiva, Rio de Janeiro, v. 22, n. 5, p. 1429-1440, 2017. DOI: http://dx.doi.org/10.1590/1413-81232017225.33542016. Disponível em: http://www.scielo.br/scielo. php?script=sci_arttext\&pid=S1413-81232017002501429\&Ing=en\&nrm=iso Acesso em: 10 mar. 2021.

MEIRA, Rogério Campos. As ferramentas para a melhoria da qualidade. Porto Alegre: SEBRAE, 2003.

MENDES, René; DIAS, Elizabeth Costa. Da medicina do trabalho à saúde do trabalhador. Revista de Saúde Pública, São Paulo, v. 25, n. 5, p. 341-49, 1991. Disponível em: https://www.nescon.medicina.ufmg.br/ biblioteca/imagem/2977.pdf. Acesso em: 10 mar. 2021.

NARDOCCI, Adelaide Cássia et al. Saúde Ambiental e Ocupacional. In: ROCHA, Aristides Almeida; CESAR, Chester Luiz Galvão; RIBEIRO, Helena. Saúde pública: bases conceituais. 2. ed. São Paulo: Atheneu, 2013. p. 71-114.

NARVAI, Paulo Capel; SÃO PEDRO, Paulo Frazão. Práticas de saúde pública. In: ROCHA, Aristides Almeida; CESAR, Chester Luiz Galvão; RIBEIRO, Helena. (Org.) Saúde pública: bases conceituais. 2. ed. São Paulo: Atheneu, 2013. p. 307-336.

OLIVEIRA, Luanne Alves; BALDACARA, Leonardo Rodrigo; MAIA, Maria Zoreide Brito. Afastamentos por transtornos mentais entre servidores públicos federais no Tocantins. Revista Brasileira de Saúde Ocupacional, São Paulo, v. 40, n. 132, p. 156-169, dez. 2015. DOI: https://doi.org/10.1590/03037657000092614. Disponível em: http://www.scielo.br/scielo.php?script=sci_arttext\&pid=S030376572015000200156\&lng=en\&nrm=iso. Acesso em: 10 mar. 2021.

ORGANIZAÇÃO MUNDIAL DA SAUDE (OMS). CID-10 Classificação Estatística Internacional de Doenças e Problemas Relacionados à Saúde. 10. rev. São Paulo: Universidade de São Paulo, 1997.

PATRUS, Roberto; DANTAS, Douglas Cabral.; SHIGAK, Helena Belintani. O produtivismo acadêmico e seus impactos na pós-graduação stricto sensu: uma ameaça à solidariedade entre pares? Cadernos EBAPE.BR, Rio de Janeiro, v. 13, n. 1, p. 1-18, jan.-mar., 2015. http://bibliotecadigital.fgv.br/ojs/index.php/cadernosebape/ article/view/8866. Acesso em: 10 mar. 2021.

RAMMINGER, Tatiana; NARDI, Henrique Caetano. Saúde mental e saúde do trabalhador: análise das conferências nacionais brasileiras. Psicologia: Ciência e Profissão, Brasília, DF, v. 27, n. 4, p. 680-693, dez. 2007. DOI: https://doi.org/10.1590/S1414-98932007000400009. Disponível em: http://www.scielo.br/scielo. php?script=sci arttext\&pid=S1414-98932007000400009\&Ing=en\&nrm=iso. Acesso em: 10 mar. 2021.

ROSSO, Sadi Dal. Mais trabalho: a intensificação do labor na sociedade contemporânea. São Paulo: Boitempo, 2008.

SANTI, Daniela Bulcão; BARBIERE, Ana Rita; CHEADE, Maria de Fátima Meinberg. Absenteísmo-doença no serviço público brasileiro: uma revisão integrativa da literatura. Revista Brasileira de Medicina do Trabalho, São Paulo, v. 16, n. 1, p. 71-81, 2018. Disponível em: http://www.rbmt.org.br/details/296/pt-BR. Acesso em: 10 mar. 2021.

TAISSUKE, Andreia Serafim de Negreiros. Política de atenção à saúde e segurança do trabalho do servidor público federal: avaliação de sua implantação na Universidade Federal do Ceará. 2016. 103 f. Dissertação (Mestrado Profissional em Políticas Públicas e Gestão da Educação Superior) Universidade Federal do Ceará, Fortaleza, 2016.

VASCONCELLOS, Luiz Carlos Fadel de; AGUIAR, Luciene. Saúde do Trabalhador: necessidades desconsideradas pela gestão do Sistema Único de Saúde. Saúde em Debate, Rio de Janeiro, v. 41, n. 113, p. 605-617, abr. 2017. DOI: http://dx.doi.org/10.1590/0103-1104201711320. Disponível em: http:// www.scielo.br/scielo.php?script=sci_arttext\&pid=S0103-11042017000200605\&lng=en\&nrm=iso. Acesso em: 10 mar. 2021. 
Reciis - Revista Eletrônica de Comunicação, Informação \& Inovação em Saúde, Rio de Janeiro, v. 15, n. 3, p. 680-702, jul.-set. 2021 [www.reciis.icict.fiocruz.br] e-ISSN 1981-6278

ZANIN, Fernanda da Conceição; PERNA, Paulo de Oliveira; KÜNZLE, Luis Allan; MUNTSCH, Sandra Mara Alessi. Política de atenção à saúde e segurança do trabalho do servidor público no Brasil.

Universidade e Sociedade, Brasília, DF, n. 55, p. 86-95, 2015. Disponível em: http://portal.andes.org.brl imprensa/publicacoes/imp-pub-226911099.pdf. Acesso em: 10 mar. 2021. 